\title{
Systemic Racism and Health Disparities: A Statement From Editors of Family Medicine Journals
}

\author{
Sumi M. Sexton, MD, Caroline R. Richardson, MD, Sarina B. Schrager, MD, MS, \\ Marjorie A. Bowman, MD, MPA, John Hickner, MD, MSc, \\ Christopher P. Morley, PhD, MA, Timothy F. Mott, MD, Nicholas Pimlott, MD, PhD, \\ John W. Saultz, MD, and Barry D. Weiss, MD
}

(J Am Board Fam Med 2021;34:4-5.)

The year 2020 has been marked by historic protests across the United States and the globe sparked by the deaths of George Floyd, Ahmaud Arbery, Breonna Taylor, and so many other Black people. The protests heightened awareness of racism as a public health crisis and triggered an antiracism movement. Racism is a pervasive and systemic issue that has profound adverse effects on health. ${ }^{1,2}$ Racism is associated with poorer mental and physical health outcomes and negative patient experiences in the health care system. ${ }^{3,4}$ As evidenced by the current coronavirus pandemic, race is a sociopolitical construct that continues to disadvantage Black, Latinx, Indigenous, and other People of Color. ${ }^{5-8}$ The association between racism and adverse health outcomes has been discussed for decades in the medical literature, including the family medicine literature. Today there is a renewed call to action for family medicine, a specialty that emerged as a counterculture to reform mainstream medicine, ${ }^{9}$ to both confront systemic racism and eliminate health disparities. This effort will require collaboration, commitment, education, and transformative conversations around racism, health inequity, and advocacy so that we can better serve our patients and our communities.

The editors of several North American family medicine publications have come together to address

From the American Family Physician (SMS); Annals of Family Medicine (CRR); FPM (SBS); Journal of the American Board of Family Medicine (MAB); Journal of Family Practice (JH); PRiMER (CPM); FPIN/EvidenceBased Practice (TFM); Canadian Family Physician (NP); Family Medicine (JWS); FP Essentials (DBW).

Funding: None.

Conflict of interest: None.

Corresponding author: Marjorie A. Bowman, MD, MPA, Wright State University, Dayton, OH 45435 (E-mail: marjorie.bowman@wright.edu). this call to action and share resources on racism across our readerships. We acknowledge those members of the family medicine scholar community who have been fighting for equity consistent with the Black Lives Matter movement by writing about racism, health inequities, and personal experiences of practicing as Black family physicians. While we recognize that much more work is needed, we want to amplify these voices. We have compiled a bibliography of scholarship generated by the family medicine community on the topic of racism in medicine. The collection can be accessed here: https://www.annfammed.org/ content/sharedbibliographysystemic-racism-andhealth-disparities.

While this list is likely not complete, it does include over 250 published manuscripts and demonstrates expertise as well as a commitment to addressing these complex issues. For example, in 2016, Dr. J. Nwando Olayiwola, chair of the Department of Family Medicine at Ohio State University, wrote an essay on her experiences taking care of patients as a Black family physician. ${ }^{10}$ In January of 2019, Family Medicine published an entire issue devoted to racism in education and training. ${ }^{11}$ Dr. Eduardo Medina, a family physician and public health scholar, coauthored a call to action in 2016 for health professionals to dismantle structural racism and support Black lives to achieve health equity. His recent 2020 article builds on that theme and describes the disproportionate deaths of Black people due to racial injustice and the COVID-19 pandemic as converging public health emergencies. ${ }^{12,13}$ In the wake of these emergencies a fundamental transformation is warranted, and family physicians can play a key role. 
We, the editors of family medicine journals, commit to actively examine the effects of racism on society and health and to take action to eliminate structural racism in our editorial processes. As an intellectual home for our profession, we have a unique responsibility and opportunity to educate and continue the conversation about institutional racism, health inequities, and antiracism in medicine. We will take immediate steps to enact tangible advances on these fronts. We will encourage and mentor authors from groups underrepresented in medicine. We will ensure that content includes an emphasis on cultural humility, diversity and inclusion, implicit bias, and the impact of racism on medicine and health. We will recruit editors and editorial board members from groups underrepresented in medicine. We will encourage collaboration and accountability within our specialty to confront systemic racism through content and processes in all our individual publications. We recognize that these are small steps in an ongoing process of active antiracism, but we believe these steps are crucial. As editors in family medicine, we are committed to progress toward equity and justice.

Simultaneously published in American Family Physician, Annals of Family Medicine, Canadian Family Physician, Family Medicine, FP Essentials, FPIN/Evidence Based Practice, FPM, Fournal of the American Board of Family Medicine, Fournal of Family Practice, and PRiMER.

The authors thank Renee Crichlow, MD; Byron Jasper, MD, $\mathrm{MPH}$; and Victoria Murrain, DO; for their insightful comments on this Editorial.

To see this article online, please go to: http://jabfm.org/content/ 34/1/4.full.

\section{References}

1. Institute of Medicine (US). Committee on understanding and eliminating racial and ethnic disparities in health care. Smedley BD, Stith AY, Nelson AR, eds. Unequal treatment: confronting racial and ethnic disparities in health care. Washington, DC: National Academies Press; 2003.

2. Bailey ZD, Krieger N, Agénor M, Graves J, Linos N, Bassett MT. Structural racism and health inequities in the USA: evidence and interventions. Lancet 2017;389:1453-63.

3. Ben J, Cormack D, Harris R, Paradies Y. Racism and health service utilisation: a systematic review and meta-analysis. PLoS One 2017;12: e0189900.

4. Paradies Y, Ben J, Denson N, et al. Racism as a determinant of health: a systematic review and metaanalysis. PLoS One 2015;10:e0138511.

5. American Academy of Family Physicians. Institutional racism in the health care system. 2019. Available from: https://www.aafp.org/about/policies/ all/institutional-racism.html. Accessed Sept. 15, 2020.

6. Yaya S, Yeboah H, Charles CH, Otu A, Labonte R. Ethnic and racial disparities in COVID-19-related deaths: counting the trees, hiding the forest. BMJ Glob Health 2020;5:e002913.

7. Egede LE, Walker RJ. Structural racism, social risk factors, and Covid-19-A dangerous convergence for Black Americans $\mathrm{N}$ Engl J Med 2020;383:e77.

8. Centers for Disease Control and Prevention. Health equity considerations and racial and ethnic minority groups. Updated July 24, 2020. Available from: https:// www.cdc.gov/coronavirus/2019-ncov/community/ health-equity/race-ethnicity.html. Accessed Sept. $15,2020$.

9. Stephens GG. Family medicine as counterculture. Fam Med 1989;21:103-9.

10. Olayiwola JN. Racism in medicine: shifting the power. Ann Fam Med 2016;14:267-9.

11. Saultz J. Racism. Fam Med 2019;51:1-66.

12. Hardeman RR, Medina EM, Kozhimannil KB. Structural racism and supporting black lives-The role of health professionals. N Engl J Med 2016;375: 2113-5.

13. Hardeman RR, Medina EM, Boyd RW. Stolen breaths. N Engl J Med 2020;383:197-9. 10.1056/ NEJMp2021072. Medline. 